\title{
"Impact of stature on non-communicable diseases: evidence based on Bangladesh Demographic and Health Survey, 2011 data"
}

\author{
Md Erfanul Hoque*, Mahfuzur Rahman Khokan and Wasimul Bari
}

\begin{abstract}
Background: In this paper, an attempt has been made to explore the relationship between height and occurrence of the non-communicable diseases such as diabetes and hypertension.

Methods: For the purpose of analysis, Bangladesh Demographic and Health Survey (BDHS), 2011 data was used. Bivariate analysis along with a Chi-square test was performed to examine association between height and diseases. To measure the impact of stature on diabetes and hypertension, three different logistic regression models (Model I: considering only quartiles of height, Model II: covariates of model I along with demographic variables and Model III: covariates of model II along with clinical variable) were considered.

Results: Occurrence of diabetes and hypertension was found to be inversely related with the height of participants. This inverse association was statistically significant for all three models. After controlling the demographic and clinical variables simultaneously, the odds ratio for highest quartile compared to the lowest quartile was 0.82 with $95 \%$ confidence interval $(0.69,0.98)$ for diabetes; whereas it was 0.72 with $95 \%$ confidence interval $(0.55,0.95)$ for hypertension.

Conclusions: Findings of this paper indicate that persons with shorter stature are substantially more likely to develop diabetes as well as hypertension. The occurrence of non-communicable diseases like diabetes and hypertension can be reduced by controlling genetic and non-genetic (early-life and childhood) factors that may influence the height.
\end{abstract}

Keywords: Blood glucose level, Blood pressure, Diabetes, Hypertension, Stature

\section{Background}

A rapid increase of Non-communicable diseases (NCDs) is becoming an alarming threat for the achievement of global progress in the developed and developing countries. The NCDs kill more than 36 million people each year, among them $80 \%$ of NCD death occur in low- and middle-income countries like Bangladesh [1]. This death toll will rise unless proper measures are taken. If the current trend continues, by 2020, NCDs will be responsible for $73 \%$ of total death and $60 \%$ of disease burden in the developing countries [1]. The causal risk factors of NCD risk factors operate through intermediate risk factors such as high blood pressure, elevated blood glucose level and plasma lipid levels [2]. These are the most prevalent risk factors around the world [3]. Generally,

\footnotetext{
*Correspondence: imerfan49@yahoo.com

Department of Statistics, Biostatistics \& Informatics, University of Dhaka, Dhaka 1000, Bangladesh
}

these risk factors are modifiable and preventable. Therefore, early identification and preventive behavior for these risk factors can reduce the risk of developing cardiovascular disease by $80 \%$ and risk of type II diabetes by $90 \%$ [4]. Like other developing countries, Bangladesh is making a transition in the disease and death patterns from communicable diseases to NCDs [5,6]. The prevention and control NCDs depend on the availability of information about these diseases and the intermediate biological biomarkers. The 2011 BDHS is the first national survey to include biomarker measurements for blood pressure and fasting blood glucose. In this paper, an attempt has been made to identify potential factors associated with the occurrence of diabetes, which is based on blood glucose level and hypertension, which is based on blood pressure.

The association between height of respondent and diabetes risk has been investigated by several epidemiological 
studies but it is still unclear whether height is associated as a risk factor. Height appears to be inversely related with diabetes, however there have been contravening reports about possible association of heights and diabetes [7-11]: a positive association was found in a study [10], whereas no association [12] or an inverse relation was reported in others $[8,11]$. Also, there was an association only in women [9] or men [13]. Hence, it would be interesting to find out a relationship between height and development of diabetes. In this paper, we try to investigate this relationship in the context of Bangladesh using BDHS 2011 data.

In a sample survey of non-communicable disease in an urban African adult population [14] and in some other studies [15-18], it is found that there is no association between height and hypertension risk. It is also found that short stature is associated with higher risk of cardiovascular heart disease [19-22]. A U-shaped association is found with quartiles of stature, mainly among women [23]. The leg length has recently been identified as a risk factor for the cardiovascular disease [24]. After adjusting age, gender, socioeconomic status and life style habits, longer legs were found to be associated with lower pulse pressure and lower low-density lipoprotein cholesterol [25]. In this paper, an attempt has also been made to examine the association between the height and hypertension. The potential factors that affect diabetes and hypertension are determined as well.

\section{Methods}

\section{Database}

The study used the 2011 Bangladesh Demographic and Health Survey (BDHS), a nationally representative sample survey of men and women of reproductive age that provides information on childhood mortality levels, fertility preferences, use of family planning methods, and maternal, child, and newborn health. Provision of biomarker indices of adult male and female populations is the special characteristic of this survey, which are instrumental in determining the increasing risk of NCDs. In the 2011 BDHS survey, a subsample of women and men age 35 years and older were eligible to participate in the biomarker component, which included blood pressure measurements, blood glucose testing, and height and weight measurements. There were 4,311 women and 4,524 men age 35 and older for blood pressure and blood glucose measurement. Among these individuals, 92 percent of women and 86 percent of men took part in the blood pressure measurement, and 89 percent of women and 83 percent of men participated in the blood glucose measure measurement.

In this study, the secondary data set 'Bangladesh Demographic and Health Survey, 2011 has been used. This data set was collected through a collaborative effort of the National Institute of Population Research and Training (NIPORT), ICF International (USA) and Mitra and Associates. The written informed consent was obtained from the participants prior to participation in the study and data collection was conducted confidentially. For this study, there is no need ethical approval since it is based on publically available secondary data.

\section{Definitions of diseases}

The 2011 BDHS uses WHO cut-off points for measuring fasting plasma glucose (FPG) [26]. The cut-off points correspond to the clinical classification for normal FPG levels, pre-diabetes and diabetes. If FPG is between $3.9 \mathrm{mmol} / \mathrm{l}(70 \mathrm{mg} / \mathrm{dl})$ and $6.0 \mathrm{mmol} / \mathrm{l}(108 \mathrm{mg} / \mathrm{dl})$, participants are considered to be normal. Participants with FPG value of $6.1-6.9 \mathrm{mmol} / \mathrm{l}(110-124 \mathrm{mg} / \mathrm{dl})$ are classified as prediabetic, and individuals with FPG greater than or equal to $7.0 \mathrm{mmol} / \mathrm{l}(126 \mathrm{mg} / \mathrm{dl})$ are considered as diabetic. In this paper, an individual is considered to be diabetic if his/her FPG value is greater than $6.1 \mathrm{mmol} / \mathrm{l}$ $(110 \mathrm{mg} / \mathrm{dl})$, otherwise he/she is considered to be in normal health state or non-diabetic [2].

The 2011 BDHS uses the American Heart Association guidelines for cut-off points for blood pressure measurements [27]. The cut-off points represent to the clinical classification for hypertension as they relate to the systolic and diastolic blood pressure measurement. For the purpose of analysis, in this paper, we divide individuals into two categories: having hypertension and not having hypertension. An individual is said to have hypertension if his/her systolic blood pressure is greater than $140 \mathrm{mmHg}$ or his/her diastolic blood pressure is greater than $90 \mathrm{mmHg}$ [28].

Along with two outcome variables diabetes and hypertension, we consider height as categorical variable based on quartiles, gender (male, female), education level (no education, primary, secondary, higher), wealth index (poorest, poorer, middle, richer, richest), place of residence (rural, urban), division (Dhaka, Barisal, Chittagong, Khulna, Rajshahi, Rangpur, Shylet), body mass index (BMI) category [thin (BMI < 18.5), normal (BMI 18.5-24.9), overweight $(\mathrm{BMI}>24.9)]$ as determinants of these outcomes [11-13,25,28].

To examine the relationship between different determinants and having diabetes and hypertension, first we conduct a bivariate analysis along with a Chi-square test and then we examine the effects of covariates that are found to be statistically significant in the bivariate analysis by fitting logistic regression model [29]. Since the main concern of this paper is to find a relationship between height and having diabetes and hypertension, at the stage of regression analysis, we consider three logistic regression models. These are Model 1: considering only the quartiles of height to examine the gross effect of the height; Model II: covariate of Model I along with 
demographic variables (education level, wealth index, place of residence, division) to examine the effect of height after controlling the demographic variables; and Model III: covariates in Model II along with clinical variable (BMI) to examine the effect of height after controlling the demographic as well as the clinical variables. For the purpose analysis, the SPSS for Windows (SPSS Inc., Chicago, IL, USA) is used.

\section{Results}

\section{Univariate analysis}

The mean height of respondent is found to be 1.57 meter with standard deviation 0.091 meter. The minimum and maximum heights are 1.09 and 1.87 meters, respectively. Among the participants, $51.21 \%$ are male and $48.79 \%$ are female. It is observed that $34.6 \%$ of participants have no education and $32.4 \%, 24.2 \%$, and $8.8 \%$ of respondents have primary, secondary and higher education, respectively. Most of the respondents (66.43\%) are found to reside in the rural area. The distribution of respondents among the divisions Dhaka, Barisal, Chittagong, Khulna, Rajshahi, Rangpur, Shylet are 17.12\%, 11.71\%, $17.11 \%, 13.53 \%, 13.46 \%, 13.33 \%$, and $13.74 \%$, respectively. More than half of the participants $(57.45 \%)$ are in the normal category of BMI measurement scale. It is found that $30.49 \%$ are thin and $12.06 \%$ are overweighed. Around $20 \%$ of respondents fall in the each category of wealth index. One-third of respondents (33.3\%) are found to be diabetic and $21.4 \%$ of respondents have hypertension.

\section{Bivariate analysis \\ Diabetes}

The background characteristics of the study participants by diabetes status are shown in Table 1. It is interesting to observe that prevalence of diabetes increase as height of participant decreases. Individuals who belong to the lower quartile of height are more likely to be diabetic compared to their counterparts. The percentage of diabetes is almost equal among men (33.0\%) and women (33.6\%). Considering education level it can be mentioned that if education level increases the percentage of diabetes also increases. Among the wealth index, the richest group has higher proportion of diabetics $(40.4 \%)$ whereas the other groups are more or less similar (around 31\%). Prevalence of diabetes is more in urban area (35.4\%) compared to the rural area (32.2\%). Among the divisions, participants from Chittagong are most likely to have diabetes (42.0\%), whereas this is least in the Rangpur division (28.0\%). It is observed that overweighed and thin participants are more prone to be diabetic than normal weighed participants. Among the overweighed participants, the rate of occurrence of diabetes is $50.5 \%$, whereas it is $33.6 \%$ and $30.6 \%$ for the thin and normal categories of BMI,
Table 1 Association between selected variables and the occurrence of diabetes with $p$ values

\begin{tabular}{|c|c|c|c|}
\hline \multirow[t]{3}{*}{ Characteristics } & \multicolumn{2}{|c|}{ Diabetes status } & \multirow[t]{3}{*}{$p$ value } \\
\hline & Non-diabetes & Diabetes & \\
\hline & n (\%) & n (\%) & \\
\hline \multicolumn{4}{|l|}{ Height category } \\
\hline Q1: $(\leq 1.51)$ & $854(63.8 \%)$ & $485(36.2 \%)$ & \multirow[t]{4}{*}{0.037} \\
\hline Q2: (1.51-1.583) & $865(65.7 \%)$ & $452(34.3 \%)$ & \\
\hline Q3: (1.583-1.637) & $906(67.8 \%)$ & $430(32.2 \%)$ & \\
\hline Q4: $(\geq 1.673)$ & $875(67.2 \%)$ & 429 (32.9\%) & \\
\hline \multicolumn{4}{|l|}{ Gender } \\
\hline Female & $2543(66.4 \%)$ & 1288 (33.6\%) & \multirow[t]{2}{*}{0.558} \\
\hline Male & $2503(67.0 \%)$ & $1231(33.0 \%)$ & \\
\hline \multicolumn{4}{|l|}{ Education level } \\
\hline No education & $2384(69.5 \%)$ & $1047(30.5 \%)$ & \multirow[t]{4}{*}{$<0.001$} \\
\hline Primary & $1377(66.1 \%)$ & 706 (33.9\%) & \\
\hline Secondary & 915 (65.2\%) & 489 (34.8\%) & \\
\hline Higher & $370(57.2 \%)$ & $277(42.8 \%)$ & \\
\hline \multicolumn{4}{|l|}{ Wealth index } \\
\hline Poorest & 929 (68.9\%) & 419 (31.1\%) & \multirow[t]{5}{*}{$<0.001$} \\
\hline Poorer & 935 (69.1\%) & 418 (30.9\%) & \\
\hline Middle & $1010(68.9 \%)$ & 455 (31.1\%) & \\
\hline Richer & $1090(68.8 \%)$ & $494(31.2 \%)$ & \\
\hline Richest & $1082(59.6 \%)$ & $733(40.4 \%)$ & \\
\hline \multicolumn{4}{|l|}{ Place of residence } \\
\hline Urban & $1607(64.6 \%)$ & $882(35.4 \%)$ & \multirow[t]{2}{*}{0.006} \\
\hline Rural & $3439(67.8 \%)$ & $1637(32.2 \%)$ & \\
\hline \multicolumn{4}{|l|}{ Division } \\
\hline Dhaka & 929 (70.6\%) & $387(29.4 \%)$ & \multirow[t]{7}{*}{$<0.001$} \\
\hline Barisal & 669 (59.8\%) & $450(40.2 \%)$ & \\
\hline Chittagong & $502(58.0 \%)$ & $364(42.0 \%)$ & \\
\hline Khulna & 889 (73.8\%) & $316(26.2 \%)$ & \\
\hline Rajshahi & 717 (67.1\%) & $351(32.9 \%)$ & \\
\hline Rangpur & 769 (72.0\%) & $299(28.0 \%)$ & \\
\hline Shylet & 571 (61.9\%) & $352(38.1 \%)$ & \\
\hline \multicolumn{4}{|l|}{ BMI category } \\
\hline Thin & $1062(66.4 \%)$ & $538(33.6 \%)$ & \multirow[t]{3}{*}{$<0.001$} \\
\hline Normal & 2075 (69.4\%) & 915 (30.6\%) & \\
\hline Overweight & 310 (49.5\%) & 316 (50.5\%) & \\
\hline
\end{tabular}

respectively. Note that height of participants is significantly associated with the occurrence of diabetes at $5 \%$ level of significance. The associations between diabetes levels and education level, wealth index, place of residence, division and BMI category are found to be highly significant (at 1\% level of significance). Only gender of participant shows insignificant association with levels of diabetes. 


\section{Hypertension}

The distribution of background characteristics by the levels of hypertension is given in Table 2. Like diabetic patients, occurrence of hypertension is inversely related with the height of patient. The rates of having hypertension in the four quartiles of height are $32.8 \%$, $22.4 \%, 16.2 \%$ and $17.4 \%$, respectively. This association is statistically significant with $p$ value $<0.001$. Unlike

Table 2 Association between selected variables and the occurrence of hypertension with $p$ values

\begin{tabular}{|c|c|c|c|}
\hline \multirow[t]{3}{*}{ Characteristics } & \multicolumn{2}{|c|}{ Hypertension status } & \multirow[t]{3}{*}{$p$ value } \\
\hline & No hypertension & Hypertension & \\
\hline & n (\%) & n (\%) & \\
\hline \multicolumn{4}{|l|}{ Height category } \\
\hline Q1: $(\leq 1.51)$ & $935(67.2 \%)$ & $456(32.8 \%)$ & \multirow[t]{4}{*}{$<0.001$} \\
\hline Q2: (1.51-1.583) & 1068 (77.6\%) & 309 (22.4\%) & \\
\hline Q3: (1.583-1.637) & 1168 (83.8\%) & $225(16.2 \%)$ & \\
\hline Q4: $(\geq 1.673)$ & $1138(82.6 \%)$ & $240(17.4 \%)$ & \\
\hline \multicolumn{4}{|l|}{ Gender } \\
\hline Female & 2959 (74.3\%) & 1022 (25.7\%) & \multirow[t]{2}{*}{$<0.001$} \\
\hline Male & $3243(83.0 \%)$ & $663(17.0 \%)$ & \\
\hline \multicolumn{4}{|l|}{ Education level } \\
\hline No education & $2786(77.6 \%)$ & 804 (22.4\%) & \multirow[t]{4}{*}{0.003} \\
\hline Primary & $1760(81.1 \%)$ & $411(18.9 \%)$ & \\
\hline Secondary & 1151 (79.1\%) & 305 (20.9\%) & \\
\hline Higher & 505 (75.4\%) & $165(24.6 \%)$ & \\
\hline \multicolumn{4}{|l|}{ Wealth index } \\
\hline Poorest & 1171 (83.5\%) & $232(16.5 \%)$ & \multirow[t]{5}{*}{$<0.001$} \\
\hline Poorer & 1171 (82.0\%) & $257(18.0 \%)$ & \\
\hline Middle & $1243(81.3 \%)$ & $286(18.7 \%)$ & \\
\hline Richer & $1267(77.2 \%)$ & 375 (22.8\%) & \\
\hline Richest & $1350(71.6 \%)$ & $535(28.4 \%)$ & \\
\hline \multicolumn{4}{|l|}{ Place of residence } \\
\hline Urban & $1940(74.9 \%)$ & $649(25.1 \%)$ & \multirow[t]{2}{*}{$<0.001$} \\
\hline Rural & $4262(80.4 \%)$ & 1036 (19.6\%) & \\
\hline \multicolumn{4}{|l|}{ Division } \\
\hline Dhaka & $1045(77.5 \%)$ & $304(22.5 \%)$ & \multirow[t]{7}{*}{$<0.001$} \\
\hline Barisal & 757 (80.8\%) & $180(19.2 \%)$ & \\
\hline Chittagong & $992(83.8 \%)$ & $192(16.2 \%)$ & \\
\hline Khulna & $911(73.6 \%)$ & 327 (26.4\%) & \\
\hline Rajshahi & $892(79.9 \%)$ & $225(20.1 \%)$ & \\
\hline Rangpur & 794 (72.4\%) & $302(27.6 \%)$ & \\
\hline Shylet & $811(84.0 \%)$ & 155 (16.0\%) & \\
\hline \multicolumn{4}{|l|}{ BMI category } \\
\hline Thin & $1374(82.7 \%)$ & $288(17.3 \%)$ & \multirow[t]{3}{*}{$<0.001$} \\
\hline Normal & $2444(78.0 \%)$ & $690(22.0 \%)$ & \\
\hline Overweight & 441 (67.0\%) & 217 (33.0\%) & \\
\hline
\end{tabular}

diabetes, gender of participant is significantly associated with the levels of hypertension ( $p$ value $<0.001$ ). Female participants are more likely to have hypertension than their counterpart (25.7\% versus $17.0 \%)$. The pattern of associations between levels of hypertension and education level, wealth index and place of residence are almost similar to the pattern of associations observed for the occurrence of diabetes. The rate of occurrence of hypertension significantly ( $p$ value $<0.001$ ) changes with divisions. Participants from Rangpur are most likely to have hypertension (27.6\%), whereas this is least in the Shylet division (16.0\%). It is noticed that with the increase of BMI, the occurrence of hypertension is significantly increased $(p$ value $<0.001)$.

\section{Regression analysis \\ Diabetes}

One of the main purposes of this study is to examine the effect of height of participant on the occurrence of diabetes. For this purpose, we consider three logistic regression models. The results are given in Table 3 . In Model I, only height of participants is considered to measure the unadjusted effect of height. It is observed that height is almost inversely related with the development of diabetes. For example, individual who is in the highest quartile of height are 14\% less likely to develop diabetes compared to the individual who is in the lowest quartile of height. Odds ratios for the second and third quartiles are found to be statistically significant at $5 \%$ and $10 \%$ level of significance, respectively. It is interesting to observe from Model II and Model III that the relationship between height and developing diabetes is becoming strictly inversed when demographic and clinical variables are added to the Model I. In Model II and Model III, both odds ratios for the second and third quartiles are significant at 5\% level of significance. It implies that height of participant plays an important role in developing the diabetes as it is found statistically significant even after controlling the demographic and clinical variables.

It is found from Model II that rate of occurring diabetes increases significantly with level of education and wealth index. For individual with highest education level, the occurrence of diabetes is $50 \%$ higher than the individual with no education. Those who are in the highest wealth index level are $60 \%$ more likely to have diabetes than who are in the middle level. Place of residence is not found to have statically significant effect, but regions have significant effects on diabetes. Similar results are found in the model when clinical variable BMI is added to Model II. Both thin and overweighed individuals are positively associated with the development of diabetes than their counterpart normal weighed. These effects are statistically significant at $5 \%$ and $1 \%$ level of significance, respectively. 
Table 3 Regression coefficients (Reg. Coef.) and odds ratios (OR) with $95 \%$ confidence intervals (95\% CI) of explanatory variables for the occurrence of diabetes obtained from logistic regression model

\begin{tabular}{|c|c|c|c|}
\hline Characteristics & $\begin{array}{l}\text { Model I } \\
\text { OR }(95 \% \mathrm{Cl})\end{array}$ & $\begin{array}{l}\text { Model II } \\
\text { OR }(95 \% \mathrm{CI})\end{array}$ & $\begin{array}{l}\text { Model III } \\
\text { OR }(95 \% \mathrm{CI})\end{array}$ \\
\hline \multicolumn{4}{|l|}{ Height category } \\
\hline Q1: ( 1.51$)$ (Ref) & 1.00 & 1.00 & 1.00 \\
\hline Q2: (1.51-1.583) & $0.92(0.79,1.08)$ & $0.92(0.78,1.08)$ & $0.93(0.79,1.10)$ \\
\hline Q3: (1.583-1.637) & $0.84(0.71,0.98)^{* *}$ & $0.81(0.68,0.95)^{* *}$ & $0.84(0.71,1.00)^{* *}$ \\
\hline Q4: $(\geq 1.673)$ & $0.86(0.74,1.01)^{*}$ & $0.79(0.67,0.95)^{* *}$ & $0.82(0.69,0.98)^{* *}$ \\
\hline \multicolumn{4}{|l|}{ Education level } \\
\hline No education (Ref) & & 1.00 & 1.00 \\
\hline Primary & & $1.06(0.92,1.23)$ & $1.06(0.91,1.23)$ \\
\hline Secondary & & $1.01(0.84,1.21)$ & $0.97(0.81,1.17)$ \\
\hline Higher & & $1.5(1.2,1.94)^{* * *}$ & $1.39(1.09,1.77)^{* *}$ \\
\hline \multicolumn{4}{|l|}{ Wealth index } \\
\hline Poorest & & $1.12(0.92,1.36)$ & $1.09(0.89,1.33)$ \\
\hline Poorer & & $1.15(0.95,1.39)$ & $1.13(0.93,1.37)$ \\
\hline Middle (Ref) & & 1.00 & 1.00 \\
\hline Richer & & $1.05(0.87,1.27)$ & $1.03(0.85,1.25)$ \\
\hline Richest & & $1.6(1.3,1.97)^{* * *}$ & $1.46(1.18,1.79)^{* * *}$ \\
\hline \multicolumn{4}{|l|}{ Place of residence } \\
\hline Rural (Ref) & & 1.00 & 1.00 \\
\hline Urban & & $1.06(0.93,1.23)$ & $1.11(0.96,1.29)$ \\
\hline \multicolumn{4}{|l|}{ Division } \\
\hline Dhaka (Ref) & & 1.00 & 1.00 \\
\hline Barisal & & $1.9(1.54,2.38)^{* * *}$ & $1.91(1.53,2.39)^{* * *}$ \\
\hline Chittagong & & $1.7(1.37,2.05)^{* * *}$ & $1.63(1.33,2.00)^{* * *}$ \\
\hline Khulna & & $0.85(0.69,1.05)$ & $0.83(0.67,1.03)^{*}$ \\
\hline Rajshahi & & $1.24(1.0,1.54)^{* * *}$ & $1.19(0.96,1.49)$ \\
\hline Rangpur & & $0.98(0.79,1.21)$ & $0.95(0.77,1.18)$ \\
\hline Shylet & & $1.62(1.31,2.01)^{* *}$ & $1.59(1.28,1.97)^{* * *}$ \\
\hline \multicolumn{4}{|l|}{ BMI category } \\
\hline Thin & & & $1.17(1.03,1.34)^{* *}$ \\
\hline Normal (Ref) & & & 1.00 \\
\hline Overweight & & & $2.09(1.74,2.52)^{* * *}$ \\
\hline
\end{tabular}

Notes.

${ }^{* * *} p$ value $<0.001,{ }^{* *} p$ value $<0.05,{ }^{*} p$ value $<0.10$.

\section{Hypertension}

To determine the potential factors associated with the occurrence of hypertension, following the analysis for diabetes, three logistic regression models are fitted and the results are given in Table 4. The unadjusted effect of height on the hypertension is statistically significant for all three quartiles (second, third, and fourth). Like in diabetes, it is also found that height of participant is almost inversely related with the development of hypertension. This relation remains same in the other two models (in Model II and Model III) after adjusting for demographic and clinical variables. In Model I, the odds ratio (OR) for the highest quartile is found to be 0.43 with $95 \%$ confidence interval $(\mathrm{CI})(0.36,0.52)$ and this effect is statistically significant at $1 \%$ level of significance. The prevalence of hypertension is decreased by $57 \%$ for those individuals who belong to the highest quartile of height compared to individuals in the lowest quartile. This OR is 0.74 with $95 \%$ CI $(0.57,0.97)$ in the Model II; whereas it is 0.72 in the Model III with $95 \%$ CI $(0.55$, 0.95). It indicates that as the participant is taller, lower would be the rate of developing the hypertension. These 
Table 4 Regression coefficients (Reg. Coef.) and odds ratios (OR) with $95 \%$ confidence intervals (95\% CI) of explanatory variables for the occurrence of hypertension obtained from logistic regression model

\begin{tabular}{|c|c|c|c|}
\hline Characteristics & $\begin{array}{l}\text { Model I } \\
\text { OR }(95 \% \mathrm{Cl})\end{array}$ & $\begin{array}{l}\text { Model II } \\
\text { OR }(95 \% \mathrm{Cl})\end{array}$ & $\begin{array}{l}\text { Model III } \\
\text { OR }(95 \% \mathrm{Cl})\end{array}$ \\
\hline \multicolumn{4}{|l|}{ Height category } \\
\hline Q1: ( 1.51$)$ (Ref) & 1.00 & 1.00 & 1.00 \\
\hline Q2: (1.51-1.583) & $0.59(0.50,0.70)^{* * *}$ & $0.89(0.72,1.08)$ & $0.88(0.72,1.08)$ \\
\hline Q3: (1.583-1.637) & $0.39(0.33,0.47)^{* * *}$ & $0.71(0.55,0.92)^{* *}$ & $0.69(0.53,0.90)^{* * *}$ \\
\hline Q4: $(\geq 1.673)$ & $0.43(0.36,0.52)^{* * *}$ & $0.74(0.57,0.97)^{* *}$ & $0.72(0.55,0.95)^{* *}$ \\
\hline \multicolumn{4}{|l|}{ Gender } \\
\hline Male (Ref) & & 1.00 & 1.00 \\
\hline Female & & $0.44(0.36,0.54)^{* * *}$ & $0.45(0.36,0.56)^{* * *}$ \\
\hline \multicolumn{4}{|l|}{ Education level } \\
\hline No education (Ref) & & 1.00 & 1.00 \\
\hline Primary & & $0.90(0.76,1.07)$ & $0.87(0.73,1.04)$ \\
\hline Secondary & & $0.96(0.78,1.19)$ & $0.92(0.75,1.15)$ \\
\hline Higher & & $1.26(0.96,1.65)^{*}$ & $1.14(0.87,1.50)$ \\
\hline \multicolumn{4}{|l|}{ Wealth index } \\
\hline Poorest & & $0.77(0.61,0.97)^{* *}$ & $0.78(0.62,0.99)^{* *}$ \\
\hline Poorer & & $0.84(0.67,1.05)$ & $0.86(0.68,1.08)$ \\
\hline Middle (Ref) & & 1.00 & 1.00 \\
\hline Richer & & $1.19(0.97,1.47)$ & $1.14(0.92,1.41)$ \\
\hline Richest & & $1.63(1.3,2.04)^{* * *}$ & $1.5(1.19,1.9)^{* * *}$ \\
\hline \multicolumn{4}{|l|}{ Place of residence } \\
\hline Rural (Ref) & & 1.00 & 1.00 \\
\hline Urban & & $0.92(0.79,1.08)$ & $0.94(0.80,1.11)$ \\
\hline \multicolumn{4}{|l|}{ Division } \\
\hline Dhaka (Ref) & & 1.00 & 1.00 \\
\hline Barisal & & $0.82(0.63,1.06)$ & $0.84(0.65,1.1)$ \\
\hline Chittagong & & $0.67(0.52,0.85)^{* * *}$ & $0.67(0.52,0.86)^{* * *}$ \\
\hline Khulna & & $1.44(1.15,1.79)^{* * *}$ & $1.45(1.16,1.81)^{* * *}$ \\
\hline Rajshahi & & $0.97(0.77,1.24)$ & $0.98(0.77,1.26)$ \\
\hline Rangpur & & $1.45(1.15,1.82)^{* * *}$ & $1.48(1.73,1.87)^{* * *}$ \\
\hline Shylet & & $0.71(0.55,0.92)$ & $0.73(0.56,0.95)^{* *}$ \\
\hline \multicolumn{4}{|l|}{ BMI category } \\
\hline Thin & & & $0.72(0.61,0.85)^{* * *}$ \\
\hline Normal (Ref) & & & 1.00 \\
\hline Overweight & & & $1.33(1.1,1.63)^{* * *}$ \\
\hline
\end{tabular}

Notes.

${ }^{* * *} p$ value $<0.001,{ }^{* *} p$ value $<0.05,{ }^{*} p$ value $<0.10$

results establish the fact that short stature is a potential risk factor for developing hypertension.

In Model II, the effects of demographic variables on the occurrence of hypertension are also examined along with the effect of height of respondents. It is observed that female is less likely to have hypertension compared to male. In this case, the OR is found to be 0.44 with
$95 \%$ CI $(0.36,0.54)$. Only higher education level is found to have significant impact on the hypertension. The odds of developing hypertension is $26 \%$ higher for an individual with higher education compared to an individual with no education. It is interesting to observe that the development of hypertension increases with the level of wealth index. For example, ORs are 0.77 [95\% CI: (0.61, 
0.97)] and 1.63 [95\% CI: $(1.30,2.04)]$ for the poorest and richest groups, respectively. Like in the case of diabetes, place of residence of respond is found to have no significant effect on the hypertension. Individuals from Rangpur and Khulna divisions are more prone to the hypertension compared to individuals from other divisions. In Model III, effect of BMI is examined controlling demographic variables as well as height of individuals. The pattern of effects of demographic variables in Model III is same as the pattern found in Model II. There exists a positive linear relationship between the levels of BMI and occurrence of hypertension. Thin is less likely [OR: 0.72; $95 \%$ CI: $(0.61$, $0.85)$ ] and overweighed is more likely to have hypertension compared to the individual with normal weight.

\section{Discussion and conclusions}

The aim of this study is to find out the relationship between height of respondent and the occurrence of diabetes and hypertension. For this purpose, we conduct, first, bivariate analysis and then regression analysis by fitting three different logistic regression models. In Model I, only the quartiles of height on individual is considered to examine the unadjusted effect of height on diabetes and hypertension. Effect of height is also examined in Model II by controlling demographic variables and in Model III by controlling demographic and clinical variables. From both bivariate analysis and all three logistic regression models, it is found that occurrence of diabetes and hypertension is inversely related with the height of participants and this association is statistically significant. That is, chance of developing diabetes and hypertension decreases with the increase of height of participant.

It is not clear how height is inversely related with the occurrence of diabetes. One of explanations of this inverse relation is that taller individuals have more muscle mass and muscle is the major tissue involved in uptake of glucose, against the fixed glucose load of 75 grams [7]. The dilution effect of total body water may contribute in establishing the results [7]. The possible explanations for the inverse relationship between height and the occurrence of hypertension were discussed by Lawlor et al. [24]. These are: genetic factors determining growth patterns may be associated with hypertension [30]; coronary artery vessel diameter increases with height and vessel with smaller diameters may result in clinical disease outcome with relatively smaller amounts of atherosclerosis.

Besides height of respondents, regression analyses of large databases have shown that education level, wealth index, place of residence, division, and body mass index are associated with the occurrence of diabetes. Along with the factors associated with diabetes, gender is also associated with the occurrence of hypertension.
One of the strengths of this study is the use of a nationwide large sample with comprehensive information on the occurrence of diabetes and hypertension, anthropometric and demographic variables. Anthropometric variables are collected by using direct measurement rather than selfreporting. This data set is collected through a reliable and uniform procedure, which minimize the measurement error and bias. The response rates of this study are high.

The main limitation of this paper is to use a crosssectional study and hence it may produce selection and information bias. Moreover, from this study, it may not be possible to assess the changes in the association between height and occurrence of diabetes as well as hypertension over the time. In our It suggests that shorter individuals may be at higher risk of metabolic disturbance [31]. Controlling factors which may have an influence on height could therefore result in a reduction of NCDs such as diabetes and hypertension. study, we only consider individuals of age 35 years or more since in 2011 BDHS study, men and women of age 35 or older were only considered to provide the biomarker information. Therefore, results of this study may not be extended to the other age groups. Though the variables on life styles such as diet, physical exercise, and smoking are the potential confounders for the diabetes and hypertension, these were not included in the analysis since these are not available in the 2011 BDHS data.

The result of this study reveals the fact that there exists an inverse relationship between height and the occurrence of diabetes as well as hypertension. That is, the shorter height is associated with a higher occurrence of diabetes as well as hypertension. The height may be controlled by genetic and non-genetic (early-life and childhood) factors [32-34]. Naturally, if most of the members of a family are of short stature, the next generation is likely to have short stature. But, genetic factors are entirely beyond the control of human. The non-genetic factors which may affect the height include: maternal smoking during pregnancy, prenatal and postnatal, ill health during childhood and adolescence, birth weight, mental condition during childhood and adolescence. Non-genetic factors can be controlled to some extent by following a healthy life style from the childhood.

In future studies, a cohort should be followed with longitudinal data collected at an early age prior to development of illness to establish the relationship between the stature of an individual and occurrence of noncommunicable disease. One may also take the genetic and non-genetic factors of stature into account for further analysis.

\section{Abbreviations}

BDHS: Bangladesh Demographic and Health Survey; FPG: Fasting plasma glucose; NCD: Non-communicable disease; WHO: World Health Organization. 


\section{Competing interests}

The authors declare that they have no competing interest.

\section{Authors' contribution}

EH had the original idea for the study. EH and MRK participated in the statistical analysis and helped to draft the manuscript. WB handled the supervision and prepared the manuscript. All authors read and approved the final manuscript.

\section{Acknowledgement}

We would like to thank National Institute of Population Research and Training (NIPORT), Bangladesh for allowing us to use BDHS, 2011 data for our analysis. We also thank reviewers and editors for their valuable comments and suggestions that led to significant improvements in the presentation.

\section{Received: 2 March 2014 Accepted: 16 September 2014}

Published: 26 September 2014

\section{References}

1. World Health Organization (WHO, 2010): Global Status Report on Noncommunicable Diseases. Geneva: WHO; 2010.

2. Bangladesh Demographic Health Survey Report (BDHS); 2011.

3. World Health Organization (WHO, 2003): World Health Report 2002: Reducing Risks, Promoting Healthy Life. Geneva: WHO; 2003.

4. Centers for Disease Control and Prevention (CDC) and National Center for Chronic Disease Prevention and Health Promotion: The Power of Prevention: Chronic Disease: The Public Health Challenge of the 21st Century. Atlanta, GA: CDC; 2009. http://www.cdc.gov/chronicdisease/pdf/2009-Power-of-Prevention.pdf.

5. Zaman MM, Ahmed J, Chowdhury SR, Numan SM, Parvin K, Islam MS: Prevalence of Ischemic Heart Disease in a Rural Population of Bangladesh. Indian Heart J 2007, 59:239-41.

6. Karar ZA, Alam N, Streatfield PK: Epidemiological Transition in Rural Bangladesh, 1986-2006. North America: Glob Health Action; 2009. http://www.globalhealthaction.net/index.php/gha/article/view/1904.

7. Sicree RA, Zimmet PZ, Dunstan DW, Cameron AJ, Wel-born TA, Shaw JE: Differences in height explain gender differences in the response to the oral glucose tolerance test- the AusDiab study. Diabet Med 2008, 25:296-302.

8. Snijder MB, Dekker JM, Visser M, Bouter LM, Stehouwer CD, Kostense PJ, Yudkin JS, Heine RJ, Nijpels G, Seidell JC: Association of hip and thing circumferences independent of waist circumference with the incidence of type 2 diabetes: the Hoorn study. Am J Clin Nutr 2003, 77:1192-7.

9. Bozorgmanesh M, Hadaegh F, Zabetian A, Azizi F: Impact of hip circumference and height on incident diabetes: result from 6-year follow-up in the Tehran lipid and glucose study. Diabet Med 2011, 28:1330-6.

10. Wang SL, Pan WH, Hwu CM, Ho LT, Lo CH, Lin SL, Jong YS: Incidence of NIDDM and the effects of gender, obesity, and hyperinsulinaemia in Taiwan. Diabetologia 1997, 40:1431-8.

11. Njolstad I, Amesen E, Lund-Larsen PG: Sex-differences in risk factors for clinical diabetes mellitus in a general population: a 12-years follow-up of the Finnmark Study. Am J Epidemiol 1998, 147:49-58,

12. Lorenzo C, Williams K, Stern MP, Haffner SM: Height, ethnicity and the incidence of diabetes: the San Antonio Heart Study. Metabolism 2009, 58:1530-5.

13. Schulze MB, Heideman C, Schienkiewitz A, Bergmann MM, Hoffmann K, Boeing $\mathrm{H}$ : Comparison of anthropometric characteristics in predicting the incidence of type 2 diabetes in the EPIC-Potsdam Study. Diabetes Care 2006, 29:1921-3.

14. Olatunbosun ST, Bella AF: Relationship between height, glucose intolerance and hypertension in an urban African black adult population: A case for the "thrifty phenotype" hypertension? I Natl Med Assoc 2000, 92:265-8.

15. Christakis GT, Weisel RD, Buth K, Fremes SE, Rao V, Panagiotopoulos KP, Ivanov J, Goldman BS, David TE: Is body size the cause for poor outcomes of coronary artery bypass operations in women? I Thorac Cardiovasc Surg 1995, 110:1344-56. discussion 1356-8.

16. Krahn AD, Manfreda J, Tate RB, Mathewson FAL, Cuddy TE: Evidence that height is an independent risk factor for coronary artery disease (the Manitoba Follow-Up Study). Am J Cardiol 1994, 74:398-9.
17. Ness AR, Gunnell D, Hughes J, Elwood PC, Smith GD, Burr ML: Height, body mass index, and survival in men with coronary disease: follow up of the diet and reinfarction trial (DART). J Epidemiol Community Health 2002, $56: 218-9$.

18. Rosenberg CR, Shore RE, Pasternack BS: Height and mortality after myocardial infarction. J Community Health 1995, 20:335-343.

19. Paajanen AT, Oksala NKJ, Kuukasjärvi P, Karhunen PJ: Short stature is associated with coronary heart disease: a systematic review of the literature and a meta-analysis. Eur Heart J 2010, 31:1802-9.

20. Wang N, Zhang X, Xianget YB, Yang G, Li HL, Gao J, Cai H, Gao YT, Zheng W, Shu XO: Association of adult height and its components with mortality: a report from cohort studies of 135000 Chinese women and men. Inter J Epidemiol 2011, 40:1715-26.

21. Davey S, Greenwood R, Gunnell D, Sweetnam P, Yarnell J, Elwood P: Leg length, insulin resistance, and coronary heart disease risk: the Caerphilly Study. J Epidemiol Community Health 2001, 55:867-72.

22. Gunnell D, Whitley E, Upton M, McConnachie A, Davey S, Watt G: Associations of height, leg length, and lung function with cardiovascular risk factors in the Midspan Family Study. J Epidemiol Community Health 2003, 57:141-6.

23. Sichieri R, Siqueira KS, Pereira RA, Ascherio A: Short stature and hypertension in the city of Rio de Janeiro, Brazil. Public Health Nutr 2000, 3:77-82.

24. Lawlor DA, Taylor M, Smith GD, Gunnell D, Ebrahim S: Associations of components of adult height with coronary heart disease in postmenopausal women: the British Women's Heart and Health study. Heart 2004, 90:745-9.

25. Schooling CM, Jiang C, Lam TH, Thomas GN, Heys M, Bmbs, Lao X, Zhang W, Adab P, Cheng KK, Leung GM: Height, its components, and cardiovascular risk among older Chinese: a cross-sectional analysis of the Guangzhou Biobank Cohort Study. Am J Public Health 2007, 97:1834-1. doi:10.2105/AJPH.2006.088096.

26. World Health Organization (WHO, 2006): Definition and Diagnosis of Diabetes Mellitus and Intermediate Hyperglycemia: Report of a WHO/IDF Consultation. Geneva: WHO; 2006.

27. American Heart Association (AHA, 2003): http://www.heart.org/HEARTORG/.

28. Stockwel DH, Madhavan S, Cohen H, Gibson G, Alderman MH: The determinants of hypertension awareness, treatment, and control in an insured population. Am J Public Health 1994, 84:1768-74.

29. Hosmer DW, Lemeshow S: Applied Logistic Regression. John Wiley \& Sons Inc; 2000.

30. Palmer JR, Rosenberg L, Shapiro S: Stature and the risk of myocardial infarction in women. Am J Epidemiol 1990, 132:27-32.

31. Janghorbani $M$, Amini $M$ : Association of hip circumference and height with incidence of type 2 diabetes: the isfahan Diabetes prevention Study. Acta Diabetol 2012, 49(Suppl):107-14

32. Hirschhorn JN, Lindgren CM, Daly MJ, Kirby A, Schaffner SF, Burtt NP, Altshuler D, Parker A, Rioux JD, Platko J, Gaudet D, Hudson TJ, Groop LC, Lander ES, Hirschhorn JN, Lindgren CM, Daly MJ, Kirby A, Schaffner SF, Burtt NP, Altshuler D, Parker A, Rioux JD, Platko J, Gaudet D, Hudson TJ, Groop LC, Lander ES: Genomewide linkage analysis of stature in multiple populations reveals several regions with evidence of linkage to adult height. Am J Hum Genet 2001, 69:106-16.

33. Park HS, Yim KS, Cho SI: Gender differences in familial aggregation of obesity-related phenotypes and dietary intake pattern in Korean families. Ann Epidemiol 2004, 14:486-91.

34. Li JK, Ng MC, So WY, Chiu CK, Ozaki R, Tong PC, Cockram CS, Chan JC: Phenotype and genetic clustering of diabetes and metabolic syndrome in Chinese families with type 2 diabetes mellitus. Diabetes Metab Res Rev 2006, 22:46-52.

doi:10.1186/1471-2458-14-1007

Cite this article as: Hoque et al:: "Impact of stature on non-communicable diseases: evidence based on Bangladesh Demographic and Health Survey, 2011 data". BMC Public Health 2014 14:1007. 